\title{
Thrombocytopenia in the antiphospholipid syndrome
}

Maria José Cuadrado, Fedza Mujic, Elisa Muñoz, Munther A Khamashta, Graham R V Hughes

\begin{abstract}
Objective-To determine the prevalence of thrombocytopenia in a group of patients suffering from the antiphospholipid syndrome (APS) and to investigate whether these patients may have any particular clinical or serological features. Methods-Retrospective analysis. A group of 171 APS patients seen in our department were studied for the presence of thrombocytopenia. Clinical and serological features of these patients were analysed by standard methods and each of them was correlated to the presence of thrombocytopenia and compared with those found in the group without thrombocytopenia.
\end{abstract}

Results-Each of the patients studied had a minimum of three platelet counts during the follow up period. Forty $(23.4 \%)$ were found to have thrombocytopenia; 13 with persistently low and 27 patients with intermittently low platelet counts. There were no statistically significant differences in sex, age, disease duration or diagnosis when compared with the group of APS patients without thrombocytopenia. Thrombocytopenia was associated with thrombosis in 18, with miscarriages in five, and with both of these features in 13 patients. It was the only manifestation of the APS in four patients. All patients had persistently positive tests for antiphospholipid antibodies concomitantly with the low platelet counts. No significant association was found between the presence of thrombocytopenia and clinical or serological manifestations in APS patients.

Conclusion-This study showed a prevalence of thrombocytopenia of $23.4 \%$ in APS. These patients did not present any significant clinical or serological features that distinguish them from those patients without thrombocytopenia.

(Ann Rheum Dis 1997;56:194-196)

Thrombocytopenia is frequently found in patients with the antiphospholipid syndrome (APS) and is usually mild (70-120 $\times 10^{9}$ platelets/l) and benign, with no intervention required. In a few cases it can be severe and may require aggressive treatment. Low platelet counts may appear occasionally as the sole manifestation of APS, but are more usually found along with the other APS manifestations. Apart from some reports of an association between thrombocytopenia and antiphospholipid antibodies in systemic lupus erythematosus (SLE) and primary APS (PAPS), ${ }^{1-4}$ data available concerning the prevalence, clinical and serological associations of thrombocytopenia in patients with the APS are still scarce. Recent studies have also shown that the prevalence of thrombocytopenia in patients with PAPS is similar to that seen in patients with SLE associated APS. ${ }^{56}$

In this study we have established the prevalence of thrombocytopenia in a large group of APS patients and determined whether these patients presented any particular clinical or serological association when compared with the APS patients without thrombocytopenia.

\section{Patients and methods}

A retrospective analysis of the prevalence, and clinical and serological associations of thrombocytopenia was performed in 171 APS patients attending the lupus clinic at $\mathrm{St}$ Thomas's Hospital, London. The histories of all the patients were carefully reviewed and each patient was interviewed at least once. A three page questionnaire containing all clinical and serological APS related features was used in interviewing each patient. Patients were divided in two groups, with and without thrombocytopenia, and their details were entered into a computerised registry.

A history of arterial or venous thrombosis, or both, or recurrent miscarriages or thrombocytopenia with positive tests for antiphospholipid antibodies on at least two occasions were taken as criteria for diagnosis of APS. ${ }^{7}$ Only thrombotic events verified by objective diagnostic methods were included in the study. Recurrent miscarriages were defined as two or more pregnancy loss in women without any gynaecological, anatomical or other causes. Thrombocytopenia was considered a clinical feature of APS when platelet counts of less than $150 \times 10^{9} / 1$ were found on a minimum of two occasions. Platelet counts were performed routinely in each APS patient attending the clinic (that is, every three to six months). Low platelet counts found in pregnant women receiving anticoagulation treatment (heparin) or in APS patients receiving immunosuppressive treatment were excluded from the study. These criteria were taken as the starting points of disease duration for each patient.

The two groups of APS patients were further subdivided into three subgroups. The first subgroup included APS patients without any
Correspondence to:
Dr Munther A Khamashta,
Lupus Research Unit, The
Rayne Institute, St Thomas's
Hospital, London SE1 7EH.
Accepted for publication
26 November 1996

Correspondence to:
Dr Munther A Khamashta,
Lupus Research Unit, The
Rayne Institute, St Thomas's
Hospital, London SE1 7EH.
Accepted for publication
26 November 1996 
feature of autoimmune connective tissue disorders and therefore diagnosed as PAPS. ${ }^{8}$ The other two subgroups were lupus-like disease (LLD) associated APS diagnosed in patients with fewer than four of the American Rheumatism Association criteria for the classification of SLE $^{9}$ and SLE associated APS diagnosed in patients with four or more criteria for the classification of SLE. ${ }^{9}$

All laboratory tests were performed by standard methods. The lupus anticoagulant (LA) test was not performed while patients were receiving anticoagulant treatment. Anticardiolipin antibodies (aCL) were expressed in $\operatorname{IgG}$ and $\operatorname{IgM}$ phospholipid units and were reported as negative ( $<5$ units), low positive ( 5 to 20 units), medium positive (20 to 60 units), or high positive (>60 units). Serum samples were tested at a dilution of 1:10 for antinuclear antibodies by indirect immunofluorescence on mouse liver and kidney sections. Positive samples were further tested on Hep-2 cells for patterns of antinuclear antibodies and on Crithidia luciliae for double stranded DNA antibodies. Antibodies against extractable nuclear antigen were analysed by counterimmunoelectrophoresis in which rabbit kidney and human spleen were used as a substrate.

Association between the presence of thrombocytopenia and clinical or serological features was tested by $\chi^{2}$ analysis of contingency tables. Strength of the association was measured through calculation of the odds ratio as described by Fleiss. ${ }^{10} \mathrm{~A}$ value of $\mathrm{p}<0.05$ was taken to indicate the statistical significance.

\section{Results}

All patients studied $(n=171)$ had a minimum of three platelet counts during the follow up period. Forty $(23.4 \%)$ APS patients were found to have thrombocytopenia; 13 with persistently and 27 patients with intermittently low platelet counts. Severe thrombocytopenia $\left(<50 \times 10^{9} / 1\right)$ was found in six $(17.6 \%)$ patients at some point during the follow up period. Small sample was a limiting factor for statistical analysis of their characteristics and comparison with the group of remaining 34 patients with moderate thrombocytopenia. A higher percentage of SLE associated APS $(55 \%)$ was found in the thrombocytopenic group (table 1). However, statistical analysis did not show significant differences in diagnosis between two groups of APS patients as well as in the other parameters studied, such as sex, age, follow up or disease duration (table 1).

Table 2 compares clinical and serological characteristics of APS patients with and without thrombocytopenia. Statistical analysis did not show any significant differences in parameters studied. Thrombocytopenia was the only manifestation in four APS patients. These patients were persistently positive for antiphospholipid antibodies. All of them had positive IgG aCL (one high, two medium, and one low); two had positive IgM aCL (one medium and one low); and three had positive LA. In 18 patients thrombocytopenia was associated only with thrombosis, only with
Table 1 Main demographic characteristics of APS patients with and without thrombocytopenia

\begin{tabular}{|c|c|c|}
\hline & $\begin{array}{l}\text { With } \\
\text { thrombocytopenia } \\
(n=40)\end{array}$ & $\begin{array}{l}\text { Without } \\
\text { thrombocytopenia } \\
(n=131)\end{array}$ \\
\hline \multicolumn{3}{|l|}{ Sex } \\
\hline Male & 5 & 19 \\
\hline Female & 35 & 112 \\
\hline $\begin{array}{l}\text { Age (years; mean (SD)) } \\
\text { (range) }\end{array}$ & $\begin{array}{l}35(9.5) \\
(19-60)\end{array}$ & $\begin{array}{l}38(10) \\
(15-71)\end{array}$ \\
\hline $\begin{array}{l}\text { Disease duration (years; } \\
\text { mean (SD)) } \\
\text { (range) }\end{array}$ & $\begin{array}{l}8.1(5) \\
(1.5-23)\end{array}$ & $\begin{array}{l}6.7(4) \\
(1-24)\end{array}$ \\
\hline $\begin{array}{l}\text { Follow up period (years; } \\
\text { mean (SD)) } \\
\text { (range) }\end{array}$ & $\begin{array}{l}6.2(4.2) \\
(1-9)\end{array}$ & $\begin{array}{l}5.8(4.8) \\
(1-12)\end{array}$ \\
\hline \multicolumn{3}{|l|}{ Diagnosis } \\
\hline $\begin{array}{l}\text { SLE associated APS } \\
(\%) \\
\text { LLD associated APS }\end{array}$ & $22(55)$ & $53(40)$ \\
\hline$(\%)$ & $7(8)$ & $18(14)$ \\
\hline
\end{tabular}

APS: antiphospholipid syndrome; SLE: systemic lupus erythematosus; LLD lupus-like disease.

miscarriages in five, and with both of these features in 13 patients. Miscarriages were more frequent in APS patients with thrombocytopenia $(57 \%)$ when compared with the patients without thrombocytopenia $(44 \%)$, but the difference did not reach statistical significance $(p=0.072)$. The two groups of APS patients did not present any other particular difference in clinical profiles and laboratory findings (aCL and LA).

\section{Discussion}

Previous studies have reported a similar prevalence of thrombocytopenia in smaller numbers of APS patients. ${ }^{4511}$ A higher prevalence of thrombocytopenia in men was reported in three groups, ${ }^{12-14}$ while others found no significant differences. ${ }^{15-17}$ Other characteristics, such as age and duration of disease, did not modify the expression of thrombocytopenia in our group of APS patients. Cervera et $a l^{11}$ found a similar result in a cohort of 1000 SLE patients

Table 2 Clinical and serological characteristics of APS patients with and without thrombocytopenia *

\begin{tabular}{lll}
\hline $\begin{array}{l}\text { Clinical and serological } \\
\text { manifestations }\end{array}$ & $\begin{array}{l}\text { Patients with } \\
\text { thrombocytopenia } \\
(n=40)\end{array}$ & $\begin{array}{l}\text { Patients without } \\
\text { thrombocytopenia } \\
(n=131)\end{array}$ \\
\hline Thrombosis - arterial & $17(42.5)$ & $69(53)$ \\
Recurrent thrombosis & $18(45)$ & $71(54)$ \\
Miscarriages & $25(62.5)$ & $80(61)$ \\
Livedo reticularis & $20 / 35(57)$ & $49 / 112(44)$ \\
Raynaud's & $10(25)$ & $21(16)$ \\
Heart valve involvement & $3(7.5)$ & $7(5.3)$ \\
Haemolytic anaemia & $11(27.5)$ & $30(23)$ \\
Migraine & $2(5)$ & $5(4)$ \\
Chorea & $11(27.5)$ & $34(26)$ \\
Epilepsy & $2(5)$ & $1(0.8)$ \\
Multiinfarct dementia & $8(20)$ & $16(12)$ \\
Positive lupus & $3(7.5)$ & $11(8.5)$ \\
$\quad$ anticoagulant & $31 / 37(83.8)$ & $87 / 117(74)$ \\
Positive anticardiolipin & & \\
antibodies & & $98(75)$ \\
IgG: & $33(82.5)$ & $29(22.1)$ \\
$\quad$ low & $5(12.5)$ & $38(29)$ \\
$\quad$ medium & $12(30)$ & $31(23.7)$ \\
high & $16(40)$ & $33(25)$ \\
IgM: & $14(35)$ & $18(13.7)$ \\
low & $8(20)$ & $7(6.1)$ \\
medium & $5(12.8)$ & $7(5.3)$ \\
high & $1(2.2)$ & \\
\hline \&tatical & &
\end{tabular}

* Statistical analysis did not show any significant differences in parameters tested in the two groups. Figures in parentheses are percentages. 
with and without APS. Our study also did not find any significant difference in the prevalence of thrombocytopenia in patients with PAPS and in those with SLE or lupus-like disease with associated APS. Similarly, Vianna et al concluded that the presence of SLE did not influence the expression of APS symptoms in a multicentre study of 114 APS patients. They found a higher prevalence of thrombocytopenia $(34 \%)$ in APS than our study.

A causal relation between antiphospholipid antibodies and thrombocytopenia still remains unclear and data available on these matters are controversial. Thrombocytopenia was recognised early on as a complication in patients with LA activity. ${ }^{18}{ }^{19}$ Later, it was also found in patients with high titres of IgG aCL antibodies. ${ }^{2}$ Delezé et $a l^{4}$ in a study of haemocytopenias in 500 SLE patients found that thrombocytopenia was strongly associated with $\operatorname{IgG}$ and haemolytic anaemia with $\operatorname{IgM}$ aCL isotype. Both aCL isotypes were present when patients had thrombocytopenia and haemolytic anaemia (Evan's syndrome). Furthermore, Cervera et $a l^{11}$ found an association of $\operatorname{IgM}$ isotype with both of these features. Our study could not confirm these findings as the distribution of antiphospholipid antibodies including LA was similar in patients with and without thrombocytopenia. The retrospective nature of our study and methods applied, the difference in the number of APS patients studied, and spontaneous changes in the titres of IgG and IgM aCL antibodies during the follow up period are some of the factors that could explain these differences.

Increased concentrations of antiphospholipid antibodies have been found to be common in patients with idiopathic thrombocytopenic purpura (ITP), but no clinical significance or role in mechanisms of thrombocytopenia were found. ${ }^{20}$ In an earlier study, about $30 \%$ of ITP patients had a positive aCL test at the time of diagnosis. ${ }^{21}$ Four of our patients had thrombocytopenia as the only APS manifestation. APS in these patients was diagnosed as they had persistently positive tests for antiphospholipid antibodies concomitantly with low platelet counts. There are some suggestions that platelet activation is increased in patients with positive antiphospholipid antibodies. ${ }^{22}$ Fabris $e t ~ a l^{23}$ provided evidence that platelet antigens in patients with phospholipid associated secondary immune thrombocytopenia (SLE, APS) were different from those of primary ITP and that surface glycoproteins were not involved. ITP cases were frequently found to have a higher titre of other antibodies, such as ANA, and were difficult to distinguish from other autoimmune disorders that could have associated thrombocytopenia. ${ }^{24}$ In a recent review of all aspects of thrombocytopenia in APS, Galli et al ${ }^{25}$ suggested that, if required, the same treatment as for ITP should be considered. They also concluded that moderate thrombocytopenia did not modify the treatment policy of thrombosis in APS.

In conclusion, our study found the prevalence of thrombocytopenia of $23.4 \%$ in
APS. No statistically significant differences were found that could distinguish this group of APS patients from the group without thrombocytopenia.

1 Harris EN, Asherson RA, Gharavi AE, Morgan SH, Derue G, Hughes GRV. Thrombocytopenia in SLE and related autoimmune disorders: association with anticardiolipin antibody. Br J Haematol 1985;59:227-30.

2 Harris EN, Chan JKH, Asherson RA, Aber VR, Gharavi AE, Hughes GRV. Thrombosis, recurrent fetal loss and AE, Hughes GRV. Thrombosis, recurrent fetal loss and
thrombocytopenia. Predictive value of the anticardiolipin thrombocytopenia. Predictive value of the
test. Arch Intern Med 1986;146:2153-6.

3 Delezé M, Oria CM, Alarcon-Segovia D. Occurrence of both, hemolytic anemia and thrombocytopenic purpura (Evan's syndrome), in systemic lupus erythematosus. Relationship to antiphospholipid antibodies. J Rheumatol 1988;15:611-5.

4 Delezé M, Alarcon-Segovia D, Oria CM, Sanchez-Guerrero J, Fernandez-Dominguez L, Gomez-Pacheco L, Ponce de Leon S. Hemocytopenia in systemic lupus erythematosus. Relationship to antiphospholipid antibodies. J Rheumatol 1989;16:926-30.

5 Italian registry of antiphospholipid antibodies (IR-APA). Thrombosis and thrombocytopenia in antiphospholipid syndrome (idiopathic and secondary to SLE): first report from the Italian Registry. Haematologica 1993;78:313-8.

6 Vianna JL, Khamashta MA, Ordi-Ros J, Font J, Cervera R, Lopez-Soto A, et al. Comparison of the primary and secondary antiphospholipid syndrome: a European m

7 Harris EN, Baguley E, Asherson RA, Hughes GRV. Clinical and serological features of the antiphospholipid syndrome (APS).(Abstract). Br J Rheumatol 1987;26 (suppl 2):19.

8 Asherson RA, Khamashta MA, Ordi-Ros J, Derksen RHWM, Machin SJ, Barquinero J,et al. The primary antiphospholipid syndrome: Major clinical and serological features. Medicine (Baltimore) 1989;68:366-74

9 Tan EM, Cohen AS, Fries JF, Masi AT, McShane DJ, Rothfield NF, et al. The 1982 revised criteria for the classification of systemic lupus erythematosus. Arthritis Rheum 1982;25:1271-7.

10 Fleiss JL. Statistical methods for rates and proportions. 2nd ed. New York: Wiley, 1981:32-4.

11 Cervera R, Khamashta MA, Font J, Sebastiani GD, Gil A, Lavilla P, et al. Systemic lupus erythematosus: Clinical and immunologic patterns of disease expression in a cohort of 1000 patients. Medicine 1993;72:113-24.

12 Kaufman LD, Gómez-Reino JJ, Heinicke MH, Gorevic PD. Male lupus: Retrospective analysis of the clinical and laboratory features of 52 patients, with a review of the literature. Semin Arthritis Rheum 1989;18:189-97.

13 Miller MH, Urowitz MB, Gladman DD, Killinger DW. Systemic lupus erythematosus in males. Medicine 1983; 62:327-34.

14 Sthoeger ZM, Geltner D, Rider A, Bentwich Z. Systemic lupus erythematosus in 49 Israeli males: A retrospective study. Clin Exp Rheumatol 1987;5:233-40.

15 Ward MM, Studenski S. Systemic lupus erythematosus in men: A multivariate analysis of gender differences in clinical manifestations. J Rheumatol 1990;17:220-4.

16 Hochberg MC, Boyd RE, Ahearn JM, et al. Systemic lupus erythematosus: A review of clinico-laboratory features and
immunogenic markers in 150 patients with emphasis on demographic subsets. Medicine 1985;64:285-95.

17 Blum A, Rubinow A, Galum E. Predominance of renal involvement in male patients with systemic lupus eryinvolvement in male patients with systemic
thematosus. Clin Exp Rheumatol 1991;9:206-7.

18 Gastineau DA, Kazmier FJ, Nichols WL, Bowie EJW. Lupus anticoagulant: An analysis of the clinical and laboratory features of 219 cases. Am J Hematol 1985;19:265-75.

19 Lechner K and Pabinger-Fasching I. Lupus anticoagulants and thrombosis. A study of 25 cases and the review of literature. Haemostasis 1985;15:254-62.

20 Stasi R, Stipa E, Masi M, Oliva F, Sciarra A, Perroti A, et al. Prevalence and clinical significance of elevated antiphospholipid antibodies in patients with idiopathic thrombocytopenic purpura. Blood 1994;84:4203-8.

21 Harris EN, Gharavi AE, Hedge U, Derue G, Morgan SH, Englert $\mathrm{H}$, et al. Anticardiolipin antibodies in autoimmune thrombocytopenic purpura. $\mathrm{Br} \mathrm{J}$ Haematol 1985; 59:231-4

22 Martinuzzo ME, Macluof J, Carreras LO, Levi-Toledano S. Antiphospholipid antibodies enhance thrombin-induced platelet activation and thromboxane formation. Thromb Haemost 1993;70:667-71.

23 Fabris F, Steffan A, Cordiano I, Borzini P, Luzzatto G, Randi ML, et al. Specific antiplatelet autoantibodies in patients with antiphospholipid antibodies and thrombocypatients with antiphospholipid antibodies

24 Kurata Y, Miyagawa S, Kosugi S, Kashiwagi H, Honda S, Mitzutani $\mathrm{H}$, et al. High-titer antinuclear antibodies. antiSSA/Ro antibodies and anti-nuclear RNP antibodies in patients with idiopathic thrombocytopenic purpura. Thromb Haemost 1994;71:184-7.

25 Galli M, Finazzi G, Barbui T. Thrombocytopenia in the antiphospholipid syndrome. Br J Haematol 1996;93:1-5. 